\title{
Training in Contrast Detection Improves Motion Perception of Sinewave Gratings in Amblyopia
}

\author{
Fang Hou, ${ }^{1}$ Chang-bing Huang, ${ }^{2}$ Liming Tao, ${ }^{3}$ Lixia Feng, ${ }^{3}$ Yifeng Zbou, ${ }^{*}, 1$ and \\ Zhong-Lin $\mathrm{Lu}^{*, 2}$
}

\begin{abstract}
Purpose. One critical concern about using perceptual learning to treat amblyopia is whether training with one particular stimulus and task generalizes to other stimuli and tasks. In the spatial domain, it has been found that the bandwidth of contrast sensitivity improvement is much broader in amblyopes than in normals. Because previous studies suggested the local motion deficits in amblyopia are explained by the spatial vision deficits, the hypothesis for this study was that training in the spatial domain could benefit motion perception of sinewave gratings.
\end{abstract}

Methods. Nine adult amblyopes (mean age, $22.1 \pm 5.6$ years) were trained in a contrast detection task in the amblyopic eye for 10 days. Visual acuity, spatial contrast sensitivity functions, and temporal modulation transfer functions (MTF) for sinewave motion detection and discrimination were measured for each eye before and after training. Eight adult amblyopes (mean age, $22.6 \pm 6.7$ years) served as control subjects.

RESULTs. In the amblyopic eye, training improved (1) contrast sensitivity by $6.6 \mathrm{~dB}$ (or $113.8 \%$ ) across spatial frequencies, with a bandwidth of 4.4 octaves; (2) sensitivity of motion detection and discrimination by $3.2 \mathrm{~dB}$ (or 44.5\%) and $3.7 \mathrm{~dB}$ (or $53.1 \%$ ) across temporal frequencies, with bandwidths of 3.9 and 3.1 octaves, respectively; (3) visual acuity by $3.2 \mathrm{~dB}$ (or $44.5 \%$ ). The fellow eye also showed a small amount of improvement in contrast sensitivities and no significant change in motion perception. Control subjects who received no training demonstrated no obvious improvement in any measure.

Conclusions. The results demonstrate substantial plasticity in the amblyopic visual system, and provide additional empirical support for perceptual learning as a potential treatment for amblyopia. (Invest Ophthalmol Vis Sci. 2011;52:6501-6510) DOI: 10.1167/iovs.11-7541

From the ${ }^{1}$ Vision Research Laboratory, School of Life Science, University of Science and Technology of China, Hefei Anhui, Peoples Republic of China; ${ }^{2}$ Laboratory of Brain Processes, Department of Psychology, University of Southern California, Los Angeles, California; and ${ }^{3}$ Department of Ophthalmology, the First Affiliated Hospital of Anhui Medical University, Hefei Anhui, Peoples Republic of China.

Supported by Grant 2009CB941303 from the National Basic Research Program of China, Grant 30630027 from the Natural Science Foundation of China, and Grants EY016093 and EY017491 from the National Eye Institute.

Submitted for publication March 10, 2011; revised May 3, 2011; accepted May 23, 2011.

Disclosure: F. Hou, None; C. Huang, None; L. Tao, None; L. Feng, None; Y. Zhou, None; Z.-L. Lu, None

"Each of the following is a corresponding author: Yifeng Zhou, Vision Research Laboratory, School of Life Science, University of Science and Technology of China, Hefei, Anhui 230027, China; zhouy@ustc.edu.cn.

Zhong-Lin Lu, Laboratory of Brain Processes, Department of Psychology, SGM 501, University of Southern California, Los Angeles, CA 90089; zhonglin@usc.edu.
A mblyopia, resulting from abnormal visual experience in A the "sensitive period," is a visual disorder, defined by impaired spatial vision without apparent ocular anomaly, that affects approximately $3 \%$ of the general population. ${ }^{1}$ In clinical practice, it is widely accepted that amblyopia can be treated in children less than 6 years old by occluding the affected eye or physiologically punishing (e.g., application of atropine) the fellow eye from months to years, but not in older children and adults, because traditional doctrine holds that the visual cortex is hard-wired and no longer subject to therapeutic intervention in older children and adults. ${ }^{2}$

However, many recent perceptual learning studies in adults with amblyopia find substantial improvements in visual tasks. ${ }^{3}$ For example, Levi et al. ${ }^{4,5}$ trained adult amblyopes in a Vernier acuity task and found that some of the novice trainees improved their performance in the Vernier task as well as their Snellen acuities. Li et al. ${ }^{6-8}$ reported that, after training with a position discrimination task in noise, the amblyopic subjects improved their performance in the task and their visual acuities. Polat et al. ${ }^{9}$ and Chen et al. ${ }^{10}$ trained their amblyopic subjects with a Gabor detection task with lateral flankers and found that training significantly improved contrast sensitivity and visual acuity. Zhou et al. ${ }^{11}$ and Huang et al. ${ }^{12}$ designed a simple contrast detection task and trained amblyopic subjects at their individual cutoff spatial frequencies. They found that, after training, the contrast sensitivity and visual acuity of the amblyopic eye improved by approximately $5.7 \mathrm{~dB}$ (or 92\%) and $4.6 \mathrm{~dB}$ (or $69.8 \%$ ), respectively. Most recently, Liu et al. ${ }^{13}$ found training older amblyopic children in a grating acuity task decreased grating acuity by $2.1 \%$ for those who had received patching treatment and increased grating acuity by $36.1 \%$ for those who had had no patching treatment, along with a boost of single/crowded $\mathrm{E}$ acuities by $0.9 / 0.7$ and 1.5/1.2 lines in the two groups, respectively.

Two very important issues, retention and generalizability, must be considered for perceptual learning to become an effective treatment for adults with amblyopia. Retention refers to the ability to retain the effects of learning over time. For example, Li et al. ${ }^{6}$ found that the improvement in visual acuity after perceptual learning was stable for at least 1 year. Polat et al. 9 measured the visual acuities of their amblyopic subjects 3 , 6, 9, and 12 months after training and found only a small decrement in visual acuity. Zhou et al. ${ }^{11}$ reported excellent retention of the training effects for up to 1.5 years. Liu et al. ${ }^{13}$ also found that training-induced improvements in visual acuity persisted for 1 year.

Generalizability refers to the extent to which learning effects gained in a particular stimulus, task, and context can be transferred to other stimuli, tasks, and contexts. Specificity or lack of generalizability, which is often found in perceptual learning of normal adult subjects, ${ }^{14-20}$ would render the method less effective; one would have to do perceptual learning in all the potentially important stimuli, tasks, and contexts. Studies on adults with amblyopia have found generalization of 
perceptual learning from position judgment, ${ }^{6-8}$ contrast detection with flankers, ${ }^{9,10,21}$ and contrast detection, ${ }^{11,12}$ to visual acuity. Huang et al. ${ }^{12}$ systematically studied the degree of generalizability of perceptual learning across spatial frequencies. The bandwidth of improvement was estimated from improvements in the contrast sensitivity function (CSF), that is, the difference between post- and pre-training CSFs (Fig. 1a). They found that the full bandwidth (at half height) of the improvement in the spatial frequency domain was 4.04 and 1.40 octaves for amblyopic and normal subjects, respectively, and suggested that the broader bandwidth of perceptual learning in adults with amblyopia provides an important empirical basis for using perceptual learning in amblyopia treatment.

In the present study, we investigated whether training in spatial vision could generalize to motion perception of sinewave gratings and, if so, how broad the effects are in the temporal domain. Previous studies suggested that local motion deficits in both anisometropic ${ }^{22}$ and strabismic ${ }^{23}$ amblyopia are caused by spatial vision deficits. We hypothesized that perceptual learning in the spatial domain would lead to improved motion perception of sinewave gratings.

\section{Method}

\section{Subjects}

Seventeen amblyopes, diagnosed by two ophthalmologists (the third and fourth authors) and naive to the purpose of the experiment participated in the study (for detailed information of all subjects, see Table 1). They were randomly assigned into the training (A1-A9) and control groups (A10-A17). The age of the two groups ranged from 14 to $34(22.1 \pm 5.6)$ and 14 to $36(22.6 \pm 6.7)$ years. The research adhered to the tenets of the Declaration of Helsinki and was conducted after the experimental protocol of human subjects was approved by the ethics committee of the School of Life Science, University of Science and Technology of China. Written informed consent was obtained from each participant after explanation of the nature and possible consequences of the study.

\section{Apparatus}

The stimuli were displayed on a monitor (G220; Sony, Tokyo, Japan) driven by a video card (ATI Radeon 9250; Advanced Micro Devices, Edison, NJ). The monitor had a display area of $32.8 \times 24.4 \mathrm{~cm}^{2}$, with a resolution of $640 \times 480$ pixels. The refresh rate of the monitor was set at $85 \mathrm{~Hz}$ for the contrast detection task and $160 \mathrm{~Hz}$ for the motion tasks. The mean luminance of the display was $24 \mathrm{~cd} / \mathrm{m}^{2}$. A special circuit was used to achieve 14-bit grayscale resolution. ${ }^{24}$ Stimuli were generated on-the-fly on the computer using commercial software (MatLab 7.1.0.14; The MathWorks Corp., Natick, MA) and Psychtoolbox subroutines. ${ }^{25,26}$ Participants viewed the stimuli monocularly and with their best refractive corrections. A chin/forehead rest was used to minimize head movements during the experiment. The untested eye was occluded with an opaque eye patch.

\section{Stimuli}

The vertical sinusoidal gratings for the spatial CSF test were the same as those used in our previous studies. ${ }^{11,12,27}$ The size of the gratings was $3.0 \times 3.0 \mathrm{deg}^{2}$. To minimize edge effects, a $0.5-\mathrm{deg}$ half-Gaussian ramp was added to each side of the stimulus to blend the stimuli into the background. The viewing distance for the gratings was $2.4 \mathrm{~m}$ for all subjects except $\mathrm{A} 7$, whose viewing distance was $4.8 \mathrm{~m}$. Seven spatial frequencies $(0.5,1,2,4,8,12$, and $16 \mathrm{cpd})$ were used in CSF tests for all subjects except $\mathrm{A} 7$, for whom the spatial frequencies were doubled.

The vertical sinusoidal gratings were identical for the motion detection and discrimination tests. Each grating subtended $2.5 \times 2.5$ $\mathrm{deg}^{2}$. The motion direction was either leftward or rightward. A Gaussian envelope with a $0.5 \mathrm{deg}$ SD was applied to every frame of the moving grating. The moving grating was displayed for $300 \mathrm{~ms}$, including a 25-ms linear onset ramp and a 25-ms offset ramp. Seven temporal frequencies $(1,3,9,16,24,30$, and $36 \mathrm{~Hz})$ were used in motion detection and motion direction discrimination. For the training group, the spatial frequency of the moving grating was near the spatial frequency at which the contrast threshold estimated from the pretraining CSF test was 0.05 for each individual. For the control group, the spatial frequency of the moving grating was individually chosen based on the individual's performance in the practice session. The average spatial frequencies used in the motion tasks for two groups were matched (Table 1). The spatial frequencies for the MTF tests were lower than that used in contrast sensitivity training, so that we could measure MTFs over a wide range of temporal frequencies. The viewing distance for the moving gratings was $1.2 \mathrm{~m}$.

\section{Procedure}

A two-interval forced-choice (2IFC) grating detection task was used to measure the CSFs of each subject. In each trial, a sinusoidal grating was randomly presented in one of two successive intervals, each lasting $118 \mathrm{~ms}$ and preceded by a 259-ms fixation display, in which two vertical and two horizontal line segments outside the stimulus area were used to indicate the center of the display. The two intervals, one with a grating and the other blank, were separated by $500 \mathrm{~ms}$, and a brief tone signaled each interval's onset. Participants were asked to a
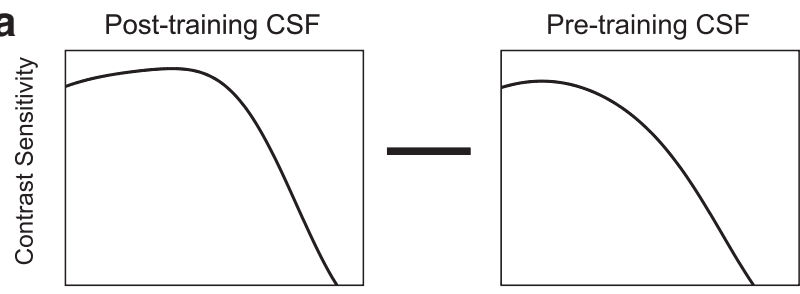

Spatial Frequency
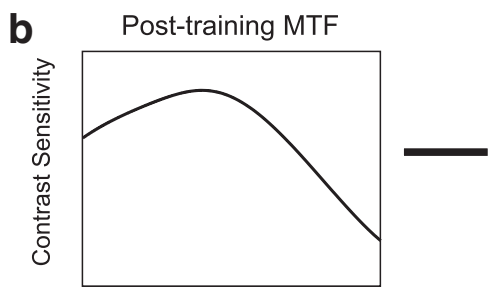

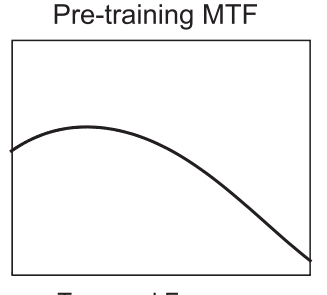

Temporal Frequency

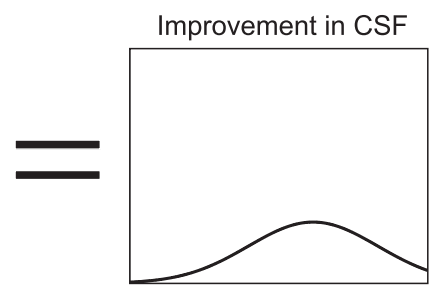

Improvement in MTF

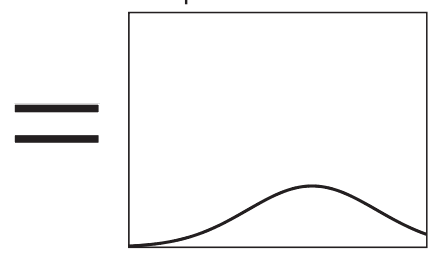

FIGURE 1. (a) The bandwidth of perceptual learning is estimated by subtracting the pre-training CSF from the post-training CSF. (b) In the temporal domain, the bandwidth of perceptual learning is estimated by subtracting the pre-training MTF from the post-training MTF. 
TABLE 1. Characteristics of Each Amblyopic Participant

\begin{tabular}{|c|c|c|c|c|c|c|c|c|c|}
\hline & Sex & Age & Eye & Type & Eye Alignment & Correction & Visual Acuity & $\begin{array}{l}\text { SF of CS } \\
\text { Training }\end{array}$ & $\begin{array}{l}\text { SF for } \\
\text { MTF }\end{array}$ \\
\hline A1 & M & 22 & $\begin{array}{l}\mathrm{AE} \\
\mathrm{FE}\end{array}$ & Strab & EXT $25 \Delta$ & $\begin{array}{l}-2.25 \mathrm{DS}:-1.00 \mathrm{DC} \times 150^{\circ} \\
-2.00 \mathrm{DS}:-0.50 \mathrm{DC} \times 50^{\circ}\end{array}$ & $\begin{aligned} & 1.07(20 / 237) \\
- & 0.07(20 / 17)\end{aligned}$ & 4 & 2 \\
\hline A2 & M & 25 & $\begin{array}{l}\mathrm{AE} \\
\mathrm{FE}\end{array}$ & Aniso & None & $\begin{array}{l}-7.00 \mathrm{DS} \\
-1.50 \mathrm{DS}\end{array}$ & $\begin{array}{l}0.87(20 / 150) \\
-0.33(20 / 9)\end{array}$ & 15 & 4 \\
\hline A3 & M & 25 & $\begin{array}{l}\mathrm{AE} \\
\mathrm{FE}\end{array}$ & Aniso & None & $\begin{array}{l}+9.25 \mathrm{DS}:+1.50 \mathrm{DC} \times 170^{\circ} \\
+5.50 \mathrm{DS}:+1.50 \mathrm{DC} \times 85^{\circ}\end{array}$ & $\begin{array}{l}0.72(20 / 106) \\
-0.12(20 / 15)\end{array}$ & 2 & 2 \\
\hline A4 & M & 22 & $\begin{array}{l}\mathrm{AE} \\
\mathrm{FE}\end{array}$ & Aniso & None & $\begin{array}{l}+6.50 \mathrm{DS}:+2.00 \mathrm{DC} \times 100^{\circ} \\
+3.50 \mathrm{DS}:+1.50 \mathrm{DC} \times 85^{\circ}\end{array}$ & $\begin{array}{l}0.98(20 / 189) \\
0.07(20 / 24)\end{array}$ & 10 & 4 \\
\hline A5 & M & 34 & $\begin{array}{l}\mathrm{AE} \\
\mathrm{FE}\end{array}$ & Aniso & None & $\begin{array}{l}+7.00 \mathrm{DS} \\
-1.00 \mathrm{DC} \times 90^{\circ}\end{array}$ & $\begin{array}{r}0.68(20 / 95) \\
-0.12(20 / 15)\end{array}$ & 8 & 4 \\
\hline A6 & M & 14 & $\begin{array}{l}\mathrm{AE} \\
\mathrm{FE}\end{array}$ & Aniso & None & $\begin{array}{l}-7.50 \mathrm{DS} \\
-4.00 \mathrm{DS}:-1.00 \mathrm{DC} \times 175^{\circ}\end{array}$ & $\begin{array}{l}0.87(20 / 150) \\
0.07(20 / 24)\end{array}$ & 2 & 2 \\
\hline A7 & M & 20 & $\begin{array}{l}\mathrm{AE} \\
\mathrm{FE}\end{array}$ & Aniso & None & $\begin{array}{l}+0.75 \mathrm{DS}: 0.25 \mathrm{DC} \times 180^{\circ} \\
-1.75 \mathrm{DS}\end{array}$ & $\begin{array}{r}0.37(20 / 27) \\
-0.03(20 / 19)\end{array}$ & 24 & 4 \\
\hline A8 & $\mathrm{F}$ & 19 & $\begin{array}{l}\mathrm{AE} \\
\mathrm{FE}\end{array}$ & Aniso & None & $\begin{array}{l}-11.00 \mathrm{DS}:-3.00 \mathrm{DC} \times 5^{\circ} \\
-1.75 \mathrm{DS}:-0.75 \mathrm{DC} \times 175^{\circ}\end{array}$ & $\begin{array}{l}0.40(20 / 50) \\
0.07(20 / 24)\end{array}$ & 8 & 1 \\
\hline A9 & $\mathrm{F}$ & 18 & $\begin{array}{l}\mathrm{AE} \\
\mathrm{FE}\end{array}$ & Strab & LET $15 \Delta$ & $\begin{array}{l}+0.50 \mathrm{DS}:+0.50 \mathrm{DC} \times 90^{\circ} \\
\text { Plano }\end{array}$ & $\begin{array}{l}0.98(20 / 189) \\
-0.03(20 / 19)\end{array}$ & 16 & 4 \\
\hline A10 & M & 18 & $\begin{array}{l}\mathrm{AE} \\
\mathrm{FE}\end{array}$ & Aniso & None & $\begin{array}{l}+1.50 \mathrm{DS}:+0.75 \mathrm{DC} \times 90^{\circ} \\
-1.75 \mathrm{DS}\end{array}$ & $\begin{array}{l}0.29(20 / 39) \\
0.05(20 / 22)\end{array}$ & None & 4 \\
\hline A11 & M & 23 & $\begin{array}{l}\mathrm{AE} \\
\mathrm{FE}\end{array}$ & Aniso & None & $\begin{array}{l}+1.00 \mathrm{DS} \\
\text { Plano }\end{array}$ & $\begin{array}{l}0.77(20 / 119) \\
-0.22(20 / 12)\end{array}$ & None & 2 \\
\hline A12 & M & 21 & $\begin{array}{l}\mathrm{AE} \\
\mathrm{FE}\end{array}$ & Aniso & None & $\begin{array}{l}+4.62 \mathrm{DS}(\mathrm{RGPCL}) \\
\text { Plano }\end{array}$ & $\begin{array}{l}0.95(20 / 178) \\
0.00(20 / 20)\end{array}$ & None & 2 \\
\hline A13 & M & 14 & $\begin{array}{l}\mathrm{AE} \\
\mathrm{FE}\end{array}$ & Aniso & None & $\begin{array}{l}+3.50 \mathrm{DS} \\
\text { Plano }\end{array}$ & $\begin{array}{r}0.19(20 / 31) \\
-0.25(20 / 11)\end{array}$ & None & 4 \\
\hline A14 & $\mathrm{F}$ & 36 & $\begin{array}{l}\mathrm{AE} / \mathrm{LE} \\
\mathrm{AE} / \mathrm{RE}\end{array}$ & Ametropia & None & $\begin{array}{l}+16.00 \mathrm{DS} \\
+16.00 \mathrm{DS}\end{array}$ & $\begin{array}{l}0.68(20 / 95) \\
0.67(20 / 95)\end{array}$ & None & 2 \\
\hline A15 & M & 28 & $\begin{array}{l}\mathrm{AE} \\
\mathrm{FE}\end{array}$ & Aniso & None & $\begin{array}{l}-9.75 \mathrm{DS}:-1.00 \mathrm{DC} \times 165^{\circ} \\
-1.00:-0.50 \mathrm{DC} \times 160^{\circ}\end{array}$ & $\begin{array}{l}0.18(20 / 30) \\
0.14(20 / 28)\end{array}$ & None & 2 \\
\hline A16 & M & 21 & $\begin{array}{l}\mathrm{AE} \\
\mathrm{FE}\end{array}$ & Strab & RXT $10 \Delta$ & $\begin{array}{l}+1.25 \mathrm{DS}:+0.50 \mathrm{DC} \times 180^{\circ} \\
+1.00 \mathrm{DS}\end{array}$ & $\begin{array}{r}0.85(20 / 142) \\
-0.21(20 / 12)\end{array}$ & None & 4 \\
\hline A17 & M & 20 & $\begin{array}{l}\mathrm{AE} \\
\mathrm{FE}\end{array}$ & Aniso & None & $\begin{array}{l}+1.50 \mathrm{DC} \times 90^{\circ} \\
-1.50 \mathrm{DS}:+0.75 \mathrm{DC} \times 180^{\circ}\end{array}$ & $\begin{array}{r}0.37(20 / 47) \\
-0.02(20 / 19)\end{array}$ & None & 2 \\
\hline
\end{tabular}

Visual acuity is expressed both in logMAR (MAR, minimum angle of resolution in arc min) and fractions listed in the brackets. SF of CS training, the spatial frequency of grating used in contrast sensitivity training. SF for MTF, the spatial frequency of moving sinewave gratings used in MTF tests. AE, amblyopic eye; FE, fellow eye; LE, left eye; RE, right eye; Aniso, anisometropia; Strab, strabismus; RGPCL, hard corneal contact lens.

indicate which interval contained the grating via two keys on the computer keyboard. A new trial started $500 \mathrm{~ms}$ after each response. No feedback was provided.

To measure the contrast thresholds for motion detection, a 2IFC moving grating detection task was used. In each trial, two $300-\mathrm{ms}$ intervals, each signaled by a brief tone and preceded by a $256-\mathrm{ms}$ fixation display, were presented successively. A moving grating was randomly displayed in one of the two intervals. Subjects were asked to indicate which interval contained the moving grating via two different keys. A new trial started $256 \mathrm{~ms}$ after each response. No feedback was provided.

To measure the contrast thresholds for motion direction discrimination, a two-alternative forced-choice (2AFC) motion direction discrimination task was used. In each trial, a fixation frame was first shown for $256 \mathrm{~ms}$. A moving grating, either moving to the left or right, was then presented for $300 \mathrm{~ms}$. A brief tone signaled the onset of the stimuli. Subjects were asked to indicate the direction of the motion via two different keys. A new trial started $256 \mathrm{~ms}$ after each response. No feedback was provided.

A three-down, one-up staircase ${ }^{28}$ that converges to $79.3 \%$ correct was used to measure contrast thresholds in all tests. The signal contrast was decreased by $10 \%$ (multiplied by 0.9 ) after every three consecutive correct responses, and increased by $10 \%$ (multiplied by 1.1 ) after every incorrect response.

The same 2IFC sinusoidal grating detection task was also used in the training phase. Each subject was trained near his or her cutoff spatial frequency, defined as the spatial frequency at which the contrast threshold from the pre-training CSF measurement of the amblyo- pic eye was 0.5. During training, feedback was provided after each correct response. The three-down, one-up staircase method was also used to track the contrast threshold through the whole training session.

\section{Experimental Design}

Subjects in the training group went through three phases: pre-training tests, training, and post-training retests. In the pre- and post-training tests, visual acuities, and CSFs of both eyes were measured first, and then the modulation transfer functions (MTFs) of motion detection and discrimination in both eyes. The order of motion detection and discrimination measurements was counterbalanced across subjects. In the training phase, participants practiced on grating detection in 10 sessions. Participants in the control group took the same set of tests and retests of visual acuity, and MTFs of motion detection and discrimination with a 10-day interval between them, but no CSF measurements and grating detection training.

CSFs were measured in seven spatial frequencies, each with one staircase of 100 trials. MTFs for motion detection and motion direction discrimination were measured in seven temporal frequencies, each with one staircase of 100 trials. All spatial or temporal frequency conditions and therefore staircases were intermixed in a given task.

Subjects were given 100 practice trials in the amblyopic eye before each pre-training test. The results of these trials were used to provide rough estimates of the thresholds and set the starting contrasts of the staircases.

In the training phase, subjects were trained to detect gratings near the cutoff spatial frequencies in their amblyopic eyes. A training ses- 
sion contained nine blocks with 120 trials in each block. Subjects took one training session per day. A session usually took 40 to 60 minutes. Subjects in the training group took 12 measurement sessions and 10 training sessions in 22 days. Subjects in the control group had eight measurement sessions and a 10-day break.

\section{Statistical Analysis}

For each observer, the magnitude of improvement for each measure (e.g., spatial contrast sensitivity) in average CSF was calculated as:

$$
I_{\text {individual }}=20 \log _{10}\left(\frac{\text { Measure }_{\text {post-training }}}{\text { Measure }_{\text {pre-training }}}\right) \mathrm{dB} \text {. }
$$

Because better visual acuity means a smaller MAR, the improvement in visual acuity was calculated as

$$
I_{\text {individual }}=20 \log _{10}\left(\frac{\text { MAR }_{\text {pre-training }}}{\text { MAR }_{\text {post-training }}}\right) \mathrm{dB} \text {. }
$$

We report

$$
I_{\text {group }}=\frac{\sum I_{\text {individual }}}{N}
$$

where $N$ is the total number of participants in a group, as the average magnitude of improvement for each group.

The percentage improvement was calculated as: $P_{\text {group }}=\left(10^{I_{\text {group }} / 20}-\right.$ 1) $100 \%$.

To estimate the area under the CSF and MTF (for detection and direction discrimination), the log truncated parabolic (TP) $\operatorname{model}^{29-31}$ was used to fit the measured CSFs and MTFs:

$$
\log _{10}(\text { CSF or MTF })=\left\{\begin{array}{l}
\log _{10}\left(\gamma_{\max }\right)-\delta, \quad \log _{10}(s f)<\log _{10}\left(f_{\max }\right)-\beta / 2 \sqrt{-\delta / \log _{10}(0.5)} \\
\log _{10}\left(\gamma_{\max }\right)+\log _{10}(0.5)\left(\frac{\log _{10}(s f)-\log _{10}\left(f_{\max }\right)}{\beta / 2}\right)^{2}, \text { otherwise }
\end{array}\right.
$$

where $\gamma_{\max }$ is the peak gain (sensitivity), $f_{\max }$ is the peak spatial or temporal frequency, $\beta$ represents the bandwidth that describes the function's full width at half-maximum (in octaves), and $\delta$ represents the low-frequency truncation level.

\section{Results}

\section{Training Effects in Spatial Vision}

Training near individuals' cutoff spatial frequencies led to significant improvements in contrast sensitivity (one-tailed paired $t$-test, $\left.t_{8}=-4.02 ; P<0.005\right)$ in the amblyopic eye. Averaged across subjects, the mean contrast sensitivity at the training frequency improved $9.2 \mathrm{~dB}$ (SE: 2.4 ) or $188.4 \%$ (31.8). The average learning curve, including data in both test and training sessions, plotted as log (sensitivity) versus log (training sessions), is shown in Figure 2. The slope of the learning curve is $0.30\left(r^{2}=0.69 ; P<0.005\right)$.

Training also led to significant improvements in contrast sensitivity in other spatial frequencies in the amblyopic eye (Fig. 3a). A two-way ANOVA was performed on the data in the four lowest spatial frequency conditions-0.5, 1, 2, and 4 cpd-because thresholds were not measurable for some participants in higher spatial frequencies. The result showed that the training effect was significant $\left(F_{1,7}=16.53 ; P<0.01\right)$. Contrast sensitivity improvement varied significantly with spatial frequency $\left(F_{3,21}=3.37 ; P<0.05\right)$, but there was no significant interaction between training and spatial frequency $\left(F_{3,21}=0.70, P>0.5\right)$. Averaged over subjects and spatial frequencies, contrast sensitivity improved $6.6 \mathrm{~dB}(0.9)$ or $113.8 \%(10.9)$

Training in the amblyopic eye also improved contrast sensitivity in the fellow eye. At the training frequency, contrast sensitivity improved $3.4 \mathrm{~dB}(1.7)$ or $47.9 \%$ (21.6) on average after training (one-tailed paired $t$-test: $t_{8}=-2.03 ; P<0.05$ ). The magnitude of improvement in the fellow eye was significantly smaller than that in the amblyopic eye (paired $t$-test: $t_{8}=$ 2.83; $P<0.05$ one-tailed). A two-way ANOVA showed that contrast sensitivities in other spatial frequencies also improved $\left(F_{1,7}=6.48 ; P<0.05\right)$. Averaged across frequencies and subjects, the magnitude of improvement was $1.1 \mathrm{~dB}(0.4)$ or $13.5 \%$ (4.7) for the fellow eye (Fig. 3b).
After training, visual acuity in the amblyopic eyes improved $3.2 \mathrm{~dB}(0.7)$ or $44.5 \%(8.4)$ (paired $t$-test: $t_{8}=3.82 ; P<0.01$; Fig. 4). There was no significant difference between the visual acuities before and after training in the fellow eye (paired $t$-test: $\left.t_{8}=1.22 ; P>0.10\right)$. For the control group, there was no significant change in the amblyopic (paired $t$-test: $t_{8}=0.45$; $P>0.50$ ) and fellow eyes (paired $t$-test: $t_{8}=1.46 ; P>0.15$ ).

\section{Effects of Training on Motion Perception}

In the training group, perceptual learning in grating detection in the amblyopic eye significantly improved contrast sensitivity of motion detection in the amblyopic eye (two-way ANOVA: $F_{1,8}=9.26 ; P<0.05$; Fig. 5a). Averaged across temporal

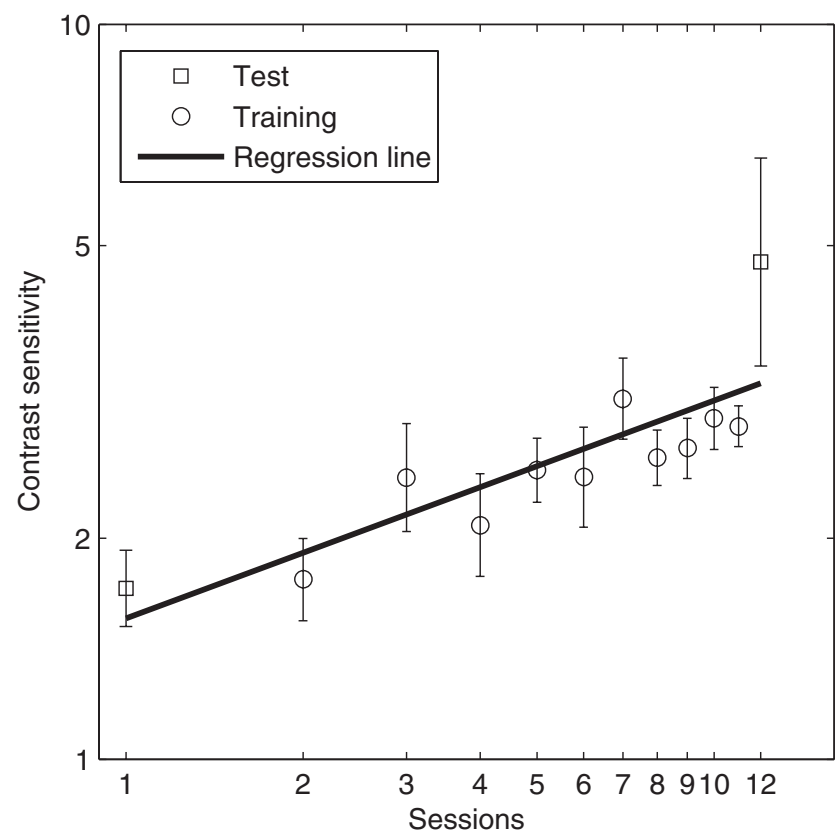

FIGURE 2. Average learning curve of the training group. ( $\square$ ) contrast sensitivities measured in the pre- and posttest phases; $(O)$ Contrast sensitivities in the training sessions. Error bars, SE. Regression was performed on the data from the test and training sessions. 

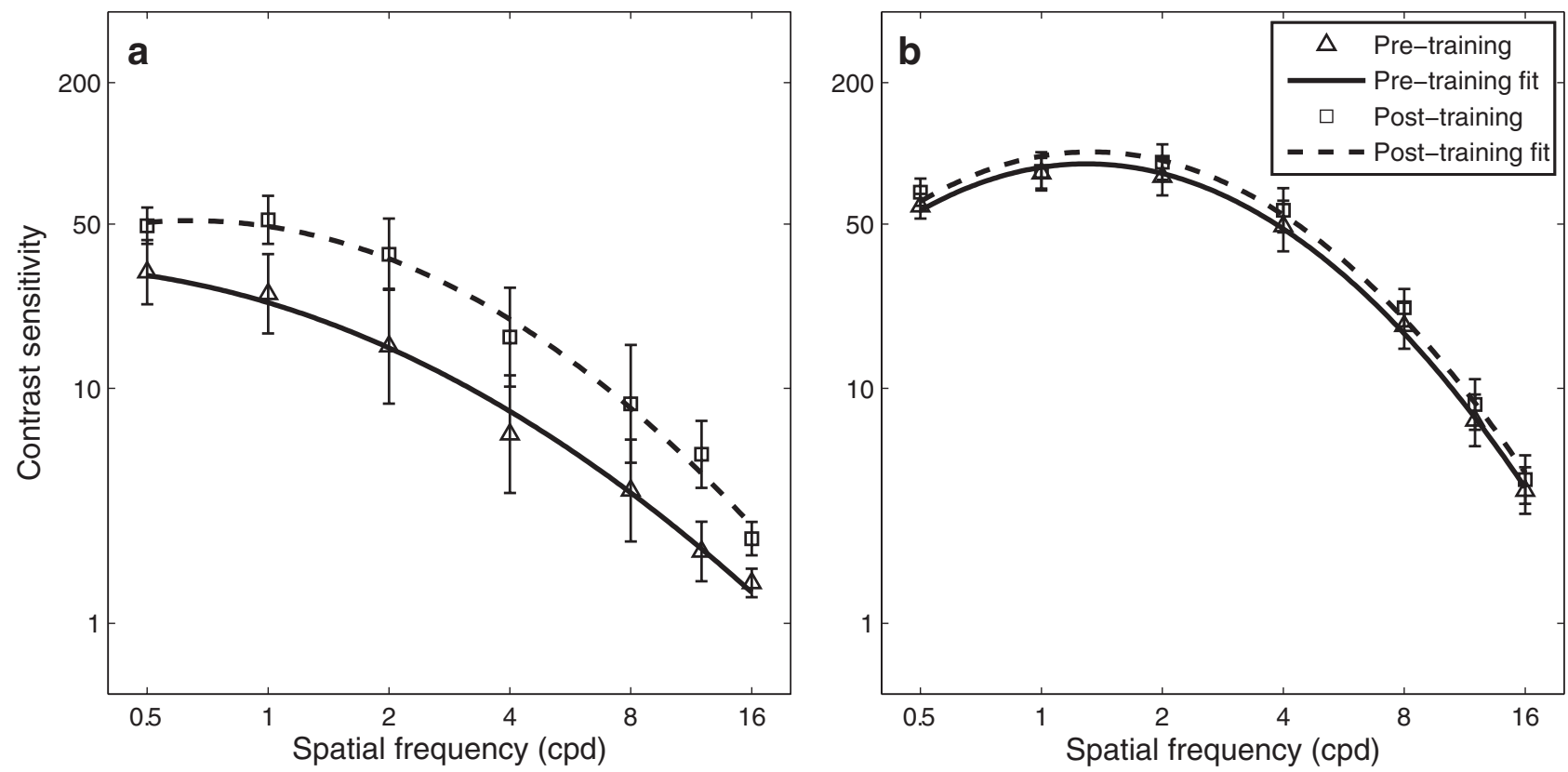

Figure 3. Pre- and post-training spatial CSFs of the amblyopic (a) and fellow eyes (b) in the training group. Solid and dashed curves: the best-fitting TP model for pre- and post-training CSFs, separately.

frequencies and subjects, contrast sensitivity in motion detection improved $3.2 \mathrm{~dB}(0.5)$ or $44.5 \%$ (5.9). Although contrast threshold in motion detection varied significantly with temporal frequency $\left(F_{4,32}=71.98 ; P<0.0001\right)$, there was no significant interaction between training and temporal frequency $\left(F_{3,24}=1.54 ; P>0.20\right)$. There was no significant improvement in contrast sensitivity of motion detection in the fellow eyes (two-way ANOVA, training effect, $F_{1,8}=0.17 ; P>$ 0.50; Fig. 5b).

Perceptual learning in grating detection in the amblyopic eye also improved contrast sensitivity of motion direction discrimination in the amblyopic eyes (two-way ANOVA, $F_{1,8}=9.92 ; P<$ 0.05; Fig. 6a). Averaged across temporal frequencies and sub-

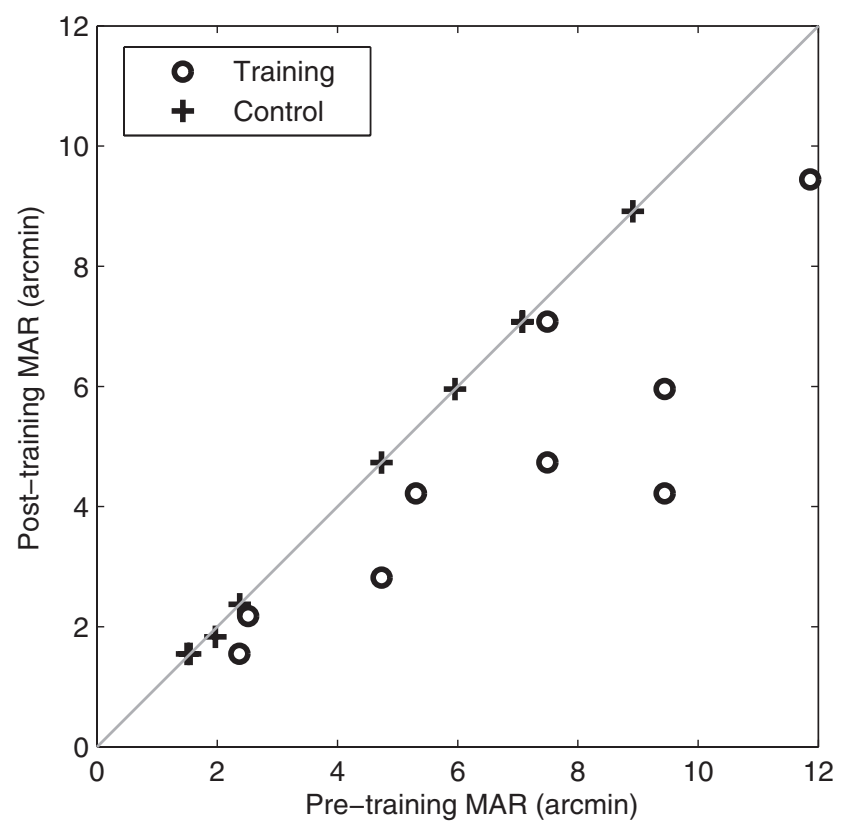

Figure 4. Visual acuities of the amblyopic eye in the training and control group. jects, contrast sensitivity in motion direction discrimination improved 3.7 (0.7) dB or $53.1 \%$ (8.4). Although contrast threshold in motion direction discrimination varied significantly with temporal frequency $\left(F_{3,24}=13.11 ; P<0.0001\right)$, there was no significant interaction between training and temporal frequency $\left(F_{3,24}=0.70 ; P>0.50\right)$. There was no significant improvement in contrast sensitivity of motion direction discrimination in the fellow eyes (two-way ANOVA, training effect, $F_{1,8)}=0.10 ; P>0.50$; Fig. $6 \mathrm{~b}$ ).

In the control group, there was no significant difference between the modulation transfer functions for motion detection and discrimination in pre- and post-training tests in both the amblyopic and fellow eyes (Figs. 5c, 5d, 6c, 6d).

\section{Bandwidth Analysis}

For the training group, we computed the bandwidth of perceptual learning in both the spatial and motion perception domains. ${ }^{12}$ Specifically, we computed the difference (improvement) between the post-training and pre-training CSFs (Fig. 1a) and modulation transfer functions (Fig. 1b) and estimated the bandwidth of the improvements.

According to the method of Huang et al., ${ }^{12}$ we calculated the bandwidth of the improvement in the spatial CSF. The magnitudes of improvement were normalized to the observed improvement at the training frequency, and the spatial frequencies were normalized to the training frequency. The normalized improvements in each participant were pooled. The spatial frequencies were divided into seven bins: $(-5,-4),(-4,-3),(-3,-2),(-2,-1),(-1,0), 0$, and $(0,2)$. The data within each bin were averaged, weighted by the SD of each bin, and fitted by a Gaussian function:

$$
a \cdot \exp \left\{-\left[\frac{\log (s f)-\log \left(s f_{0}\right)}{\sigma}\right]^{2}\right\}
$$

The bandwidth of the improvement was defined as: $2 \sqrt{\ln (2)} \cdot \sigma$. A bootstrap procedure was adopted to estimate the SD of the bandwidth. The mean (SE) bandwidth of the contrast sensitivity improve- 

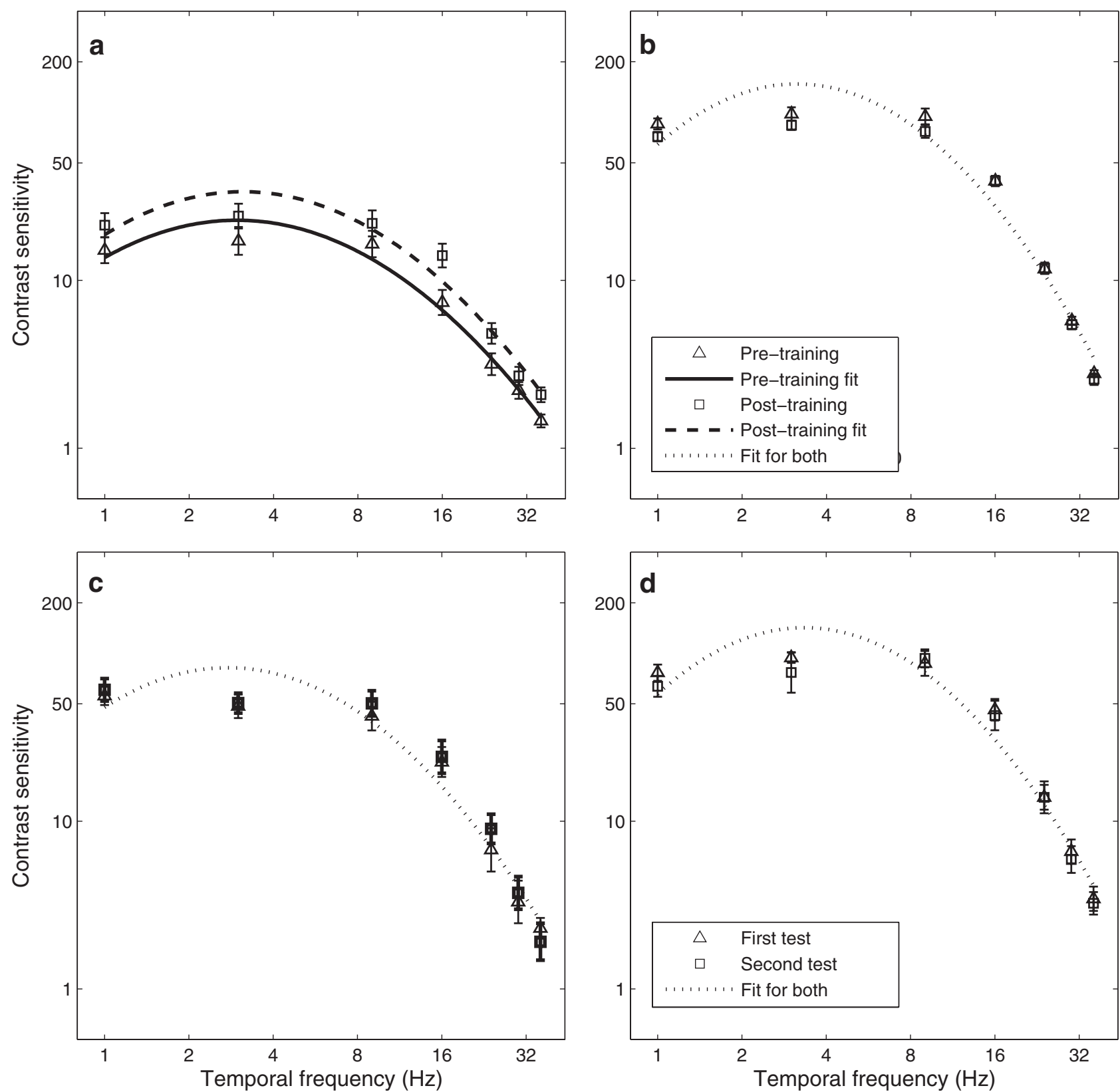

FigURE 5. (a) Pre- and post-training temporal MTFs for motion detection of the amblyopic eye in the training group are plotted. (b) Pre- and post-training temporal MTFs for motion detection of the fellow eye in the training group are plotted. For the control group, MTFs for motion detection measured in two tests of the amblyopic eye are plotted in (c), and those of the fellow eye are plotted in (d). (a) Solid and dashed curves: the best-fitting TP models for pre- and post-training MTFs, separately. There was no significant difference between the two MTFs in (b), (c), and (d). Dotted curve: the best-fitting TP model for pre- and post-training or the first and second MTFs.

ment in the amblyopic eye was 4.4 octaves $(0.05)$, comparable to the results in Huang et al. $^{12}$

A similar bandwidth analysis was conducted on the improvement in contrast sensitivity in motion detection and motion direction discrimination. For each participant, the improvements in contrast sensitivities in the motion tasks were normalized to his or her maximum magnitude of improvements. The data were averaged at each temporal frequency and weighted by the corresponding SD. A Gaussian function was used to fit the data (Fig. 1b). The SD of the fitted bandwidth was estimated through a bootstrap procedure. For the motion detection task, the mean (SE) bandwidth of learning improvement was 3.9 octaves $(0.1)$. For the motion direction discrimination task, the bandwidth of learning was 3.1 octaves $(0.1)$.

\section{A Multivariate Analysis}

To identify factors that are important for improvement after perceptual learning, we performed a multivariate linear regression analysis on our data, using age, pre-training visual acuity (VA, MAR in units of arc minutes), pre-training cutoff spatial frequency, and improvement at training frequency as independent variables (Table 2) and improvement in VA, improvement in cutoff frequency, improvement in the total area under the CSF, improvement in total area under the MTF in motion detection, and improvement in the total area under the MTF in motion direction discrimination as dependent variables (Table 3). Improvements in decibels were used in the analysis. The total area under the sensitivity functions 

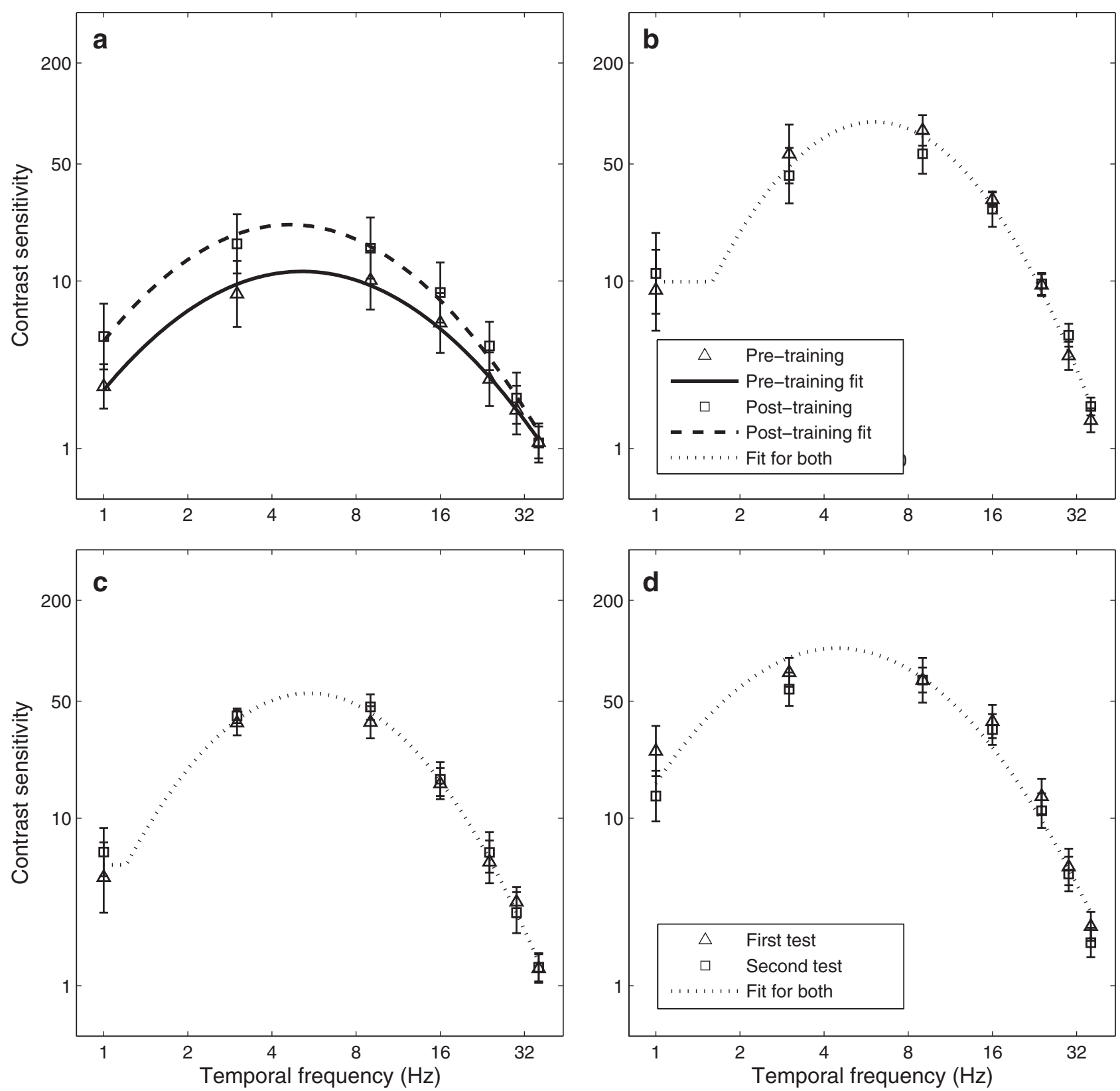

Figure 6. Pre- and post-training temporal MTFs for motion direction discrimination of the training group are plotted in (a) and (b). (a) Amblyopic eye; (b) fellow eye. MTFs for motion direction discrimination measured in two tests of the control group are plotted in (c) and (d). (c) Amblyopic eye; (d) fellow eye. (a) Solid and dashed curves: best-fitting TP models for pre- and posttraining MTFs, separately. (b, c, d, dotted curves) The best-fitting TP model for pre- and post-training or the first and second MTFs, because there was no significant difference between pre- and post-training MTFs or between the first and second MTFs.

provides a window of visibility. ${ }^{32}$ A log truncated parabolic function was used to fit to the $\mathrm{CSFs}^{29-31,33}$ and MTFs. The cutoff frequencies and areas under CSFs/MTFs were then derived from the best-fitting TP model. The regression model we used can be expressed as:

$$
\begin{aligned}
y_{\text {predicted }}=\beta_{0}+\beta_{1} \cdot \text { age }+\beta_{2} \cdot & \mathrm{VA}_{\text {pre }}+\beta_{3} \cdot \text { cut-off }_{\text {pre }} \\
& +\beta_{4} \cdot \text { improvement }_{\text {training_frequency }} .
\end{aligned}
$$

We found that the linear model provided a good account of the improvement in the total area under the $\operatorname{CSF}\left(F_{4,8}=6.50\right.$, $P<0.05)$. The improvement correlated significantly with the pre-training cutoff frequency (coefficient $\beta_{3}=-0.71 ; P<$ 0.05 ), and marginally correlated with age (coefficient $\beta_{1}=$ $-0.65 ; P=0.056$ ), suggesting more improvements for subjects with lower pre-training cutoff spatial frequency and younger age (Fig. 7). The model also provided a good account of the improvement in the total area under the MTF in motion direction discrimination $\left(F_{4,8}=17.91 ; P<0.01\right)$. Age, pre-training VA and pre-training cutoff frequency $\left(\beta_{1}=-0.68 ; \beta_{2}=\right.$ $-0.75 ; \beta_{3}=-0.61$; all $P<0.05$ ) all correlated significantly with the improvement.

To further explore the relationships between the various improvements, we computed pair-wise correlations. The improvement in cutoff frequency correlated positively to the 
TABLE 2. Independent Variables Used in Multivariate Regression

\begin{tabular}{ccccc}
\hline Subject & Age & $\begin{array}{c}\text { Pre- } \\
\text { training } \\
\text { VA } \\
\text { (arc min) }\end{array}$ & $\begin{array}{c}\text { Pre-training } \\
\text { CSF Cutoff } \\
\text { (cpd) }\end{array}$ & $\begin{array}{c}\text { Contrast Sensitivity } \\
\text { Improvement at } \\
\text { Training SF (dB) }\end{array}$ \\
\hline A1 & 22 & 11.86 & 2.76 & 11.85 \\
A2 & 25 & 7.50 & 14.69 & 3.84 \\
A3 & 25 & 5.31 & 3.82 & 8.63 \\
A4 & 22 & 9.44 & 12.19 & 21.81 \\
A5 & 34 & 4.73 & 10.17 & 2.36 \\
A6 & 14 & 7.50 & 2.49 & 14.24 \\
A7 & 20 & 2.37 & 24.28 & 2.67 \\
A8 & 19 & 2.51 & 6.69 & 14.48 \\
A9 & 18 & 9.44 & 13.00 & 2.96 \\
\hline
\end{tabular}

Improvements are in unit of $\mathrm{dB}$.

improvement in the area under the CSF, and the areas under the MTFs in motion detection and motion direction discrimination. The improvement in the area under CSF correlated positively to the areas under MTFs in motion detection and motion direction discrimination. The correlation between improvement in the area under MTF in motion detection and improvement in the area under MTF in motion direction discrimination was marginally significant $(P=0.063)$. See Table 4 for details.

\section{Discussion}

Our results showed that training in the amblyopic eye in a contrast detection task using stimuli at individuals' cutoff spatial frequencies improved the contrast sensitivity and visual acuity of the amblyopic eye by $6.6 \mathrm{~dB}$ (or $113.8 \%$ ) and $3.2 \mathrm{~dB}$ (or 44.5\%), respectively. Moreover, such training led to 3.2-dB (or $44.5 \%$ ) and $3.7-\mathrm{dB}$ (or $53.1 \%$ ) improvements in motion detection and discrimination after training. In comparison, amblyopic participants who received no training had no significant changes in motion perception. The result in the control group ruled out the possibility that the improved motion perception in the training group was due to a learning effect in the motion tests themselves. Taken together, we conclude that training in a contrast detection task can improve both spatial CSFs and motion perception of sinewave gratings. This result confirmed our hypothesis based on the analysis of the nature of local motion deficits in amblyopia. ${ }^{22,23}$

Physiological and psychophysical evidence suggested that amblyopia impairs global motion perception. ${ }^{34-37}$ Two stages are involved in global motion processing: a local motion stage in V1 and a global integration stage in extrastriate cortical

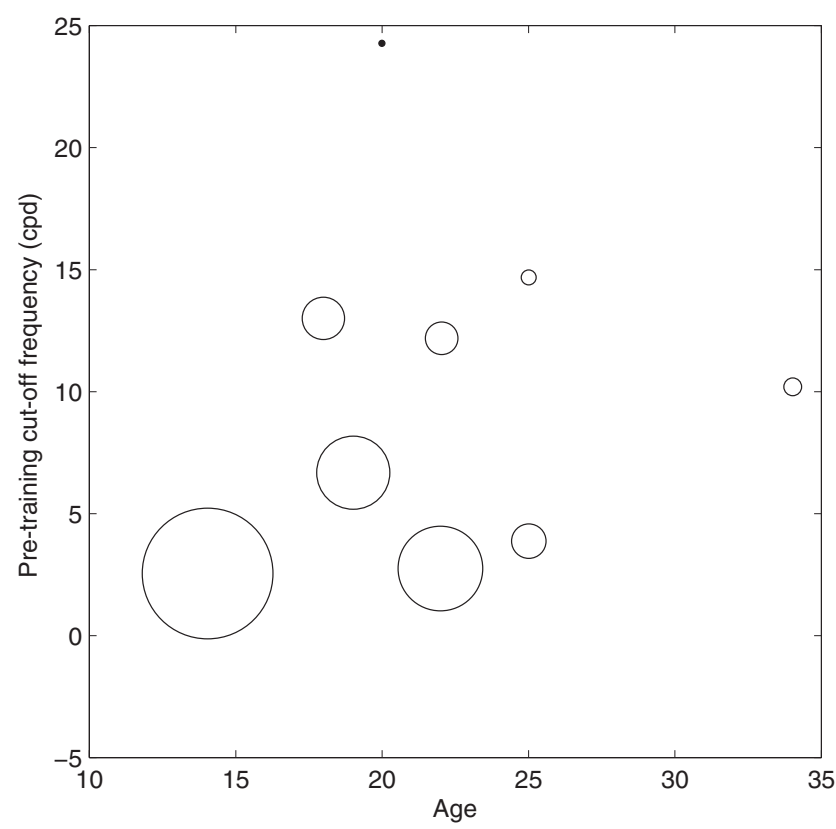

FIGURE 7. The markers represent the improvements in the area under CSF of different subjects. The size of markers indicates the magnitude of the improvements.

areas, such as MT and MST. ${ }^{38-41}$ Global motion deficits in the amblyopic visual system could result from the deficits in either stage or both. For example, Simmers et al. ${ }^{35,36}$ found that there are independent global motion processing deficits in addition to contrast sensitivity deficit in amblyopic vision. Constantinescu et al. ${ }^{37}$ reported a case of bilateral deprivation amblyopia caused by congenital cataracts. They found that there was a selective deficit for global motion processing, despite the recovery of visual acuity (20/20). We expect that training in a contrast detection task could improve global motion perception in amblyopia because it improves local motion perceptual. On the other hand, training on motion integration is necessary to improve the second stage of global motion processing.

In the motion tasks, we used stimuli at spatial frequencies that corresponded to the 0.05 threshold on the CSF, because the motion task with gratings at the training spatial frequency (i.e., the cutoff spatial frequency; threshold $=0.5$ ) in pretraining CSF was too difficult for the amblyopic participants. Because the maximum contrast sensitivity improvement was at the training spatial frequency, we believe that the improvement in motion perception at cutoff frequency would have been greater than what we have observed at the lower spatial

TABLE 3. Dependent Variables Considered in Multivariate Regression

\begin{tabular}{|c|c|c|c|c|c|}
\hline Subject & $\begin{array}{c}\text { Improvement } \\
\text { in VA }\end{array}$ & $\begin{array}{l}\text { Improvement in } \\
\text { CSF Cutoff }\end{array}$ & $\begin{array}{l}\text { Improvement in } \\
\text { CSF Area* }\end{array}$ & $\begin{array}{l}\text { Improvement in MTF } \\
\text { (Detection) Area }\end{array}$ & $\begin{array}{l}\text { Improvement in MTF } \\
\text { (Discrimination) Area* }\end{array}$ \\
\hline A1 & $1.98(-2.42)$ & $6.39(3.00)$ & 13.82 & 8.29 & 7.06 \\
\hline A2 & $0.50(-0.42)$ & $1.92(3.63)$ & 1.72 & 2.21 & 2.94 \\
\hline A3 & $2.00(-1.09)$ & $1.89(0.93)$ & 5.60 & 2.79 & 7.29 \\
\hline A4 & $7.00(-5.23)$ & $4.79(8.98)$ & 5.54 & 2.72 & -0.04 \\
\hline A5 & $4.50(-1.91)$ & $1.09(1.36)$ & 3.08 & 5.20 & 1.89 \\
\hline A6 & $3.99(-2.76)$ & $11.44(6.82)$ & 21.90 & 16.55 & 16.42 \\
\hline $\mathrm{A} 7$ & $3.70(-0.82)$ & $1.25(3.77)$ & -0.03 & 0.92 & 4.10 \\
\hline A8 & $1.25(-0.34)$ & $6.80(7.95)$ & 11.65 & 2.26 & 12.32 \\
\hline A9 & $4.00(-3.49)$ & $1.66(2.73)$ & 6.41 & -1.21 & 4.99 \\
\hline
\end{tabular}

Improvements are in unit of decibels, and the actual improvements of VA (changes of MAR in arc min) and cutoff frequency (in cycles per degree) are also listed in the brackets.

* Indicates that the variable was well predicted by our model. 
TABLE 4. Coefficients of Pairwise Correlations

\begin{tabular}{|c|c|c|c|c|c|}
\hline & $\begin{array}{l}\text { Improvement } \\
\text { in VA }\end{array}$ & $\begin{array}{l}\text { Improvement in } \\
\text { CSF Cutoff }\end{array}$ & $\begin{array}{c}\text { Improvement in } \\
\text { CSF Area }\end{array}$ & $\begin{array}{l}\text { Improvement in MTF } \\
\text { (Detection) Area }\end{array}$ & $\begin{array}{l}\text { Improvement in MTF } \\
\text { (Discrimination) Area }\end{array}$ \\
\hline Improvement in VA & 1 & 0.029 & -0.040 & 0.063 & -0.346 \\
\hline Improvement in CSF cutoff & & 1 & $0.944^{*}$ & $0.812 \ddagger$ & $0.786 \ddagger$ \\
\hline Improvement in CSF area & & & 1 & $0.819 \ddagger$ & $0.842 \dagger$ \\
\hline \multicolumn{6}{|l|}{ Improvement in MTF } \\
\hline (detection) area & & & & 1 & $0.641 \rrbracket$ \\
\hline \multicolumn{6}{|l|}{ Improvement in MTF } \\
\hline (discrimination) area & & & & & 1 \\
\hline
\end{tabular}

${ }^{*} P<0.001 ; \dagger P<0.005 ; \ddagger P<0.05 ; \rrbracket P<0.1$.

frequencies. This is probably why the average improvement in CSF was larger than those in motion detection and direction discrimination ( $6.6 \mathrm{~dB}$ vs. 3.2 and $3.7 \mathrm{~dB}$ ).

We found no significant interaction between training and spatial and temporal frequencies in CSF and MTFs. The result suggests that the improvements were general across different spatial and temporal frequencies. The bandwidth of the improvement in CSF was 4.4 octaves (0.1), similar to the findings of Huang et al. ${ }^{12}$ The broad bandwidth revealed broad generalization of perceptual learning in spatial vision. ${ }^{12}$ The bandwidths of the improvement in the temporal domain were 3.9 (0.1) and 3.1 (0.05) octaves for motion detection and discrimination, respectively, essentially spanning the entire range of temporal frequencies in our experiment. Our results suggest that training at one spatial frequency could lead to improvements in the MTFs in motion perception. Further experiments are necessary to assess whether the bandwidth in the temporal domain for amblyopia is broader than that for normal observers.

A more comprehensive examination of the effect of perceptual learning in amblyopia requires measurements of the entire spatiotemporal sensitivity surface before and after perceptual learning. The amount of data collection with traditional psychophysical procedures is insurmountable. The new generation of adaptive methods for the spatiotemporal contrast sensitivity surface ${ }^{42}$ may allow us to do that in the near future.

We did not find significant correlations between VA improvement and other parameters. Multivariate regression and pairwise correlation did not reveal any connections between VA and other factors. VA and CSF reflect different aspects of vision: VA reflects the spatial discrimination limits in highcontrast conditions, whereas CSF describes the performance of the visual system at threshold level across different spatial frequencies. In a large sample study of amblyopia, McKee et $\mathrm{al}^{43}$ found that optotype acuity and contrast sensitivity are two different dimensions of visual deficits in amblyopia. Because the VA task depends on a variety of spatial frequency channels, it may not necessarily correlate with cutoff SF. Contrast sensitivity at high spatial frequencies is still abnormal in amblyopes who are deemed "treated" based on the criterion of remediated visual acuity. ${ }^{27}$

In a related study, Huang et al. ${ }^{44}$ investigated the mechanism underlying contrast sensitivity improvements in adults with anisometropic amblyopia after perceptual learning in grating contrast detection. Using the external noise approach, ${ }^{45}$ they measured contrast thresholds in a range of external noise conditions at two performance levels (79.3\% and $70.7 \%$ ) in a grating contrast detection task through six to eight sessions of training. They found that a mixture of internal additive noise reduction and external noise exclusion underlay training induced contrast sensitivity improvements in adults with anisometropic amblyopia. We believe the same mechanisms of perceptual learning worked in the present study.
Early psychophysical studies on normal adults have demonstrated that performance improvements remain specific to basic attributes of the trained stimulus, including spatial location, ${ }^{14}$ orientation, ${ }^{16,18,46,47}$ spatial frequency, ${ }^{15}$ eye,${ }^{16,17}$ and task. ${ }^{18-20}$ Several recent studies suggest that perceptual learning could transfer to untrained stimuli or tasks. ${ }^{48-51}$ Amblyopia impairs many visual functions. It is not feasible to recover each impaired visual function by training with a corresponding task. An efficient treatment requires a large degree of generalizability to untrained stimuli or tasks. Spatial information processing is the first processing stage of motion analysis. ${ }^{52}$ In this study, we demonstrated that the training in spatial vision led to improvements in the first processing stage of motion perception in amblyopia. Our results provide additional evidence of generalization of perceptual learning in amblyopia and empirical support for perceptual learning as a potential treatment for amblyopia.

\section{References}

1. Ciuffreda KJ, Levi DM, Selenow A. Amblyopia: Basic and Clinical Aspects: Oxford, UK: Butterworth-Heinemann; 1991.

2. Moseley M. Amblyopia: treatment and evaluation. In: Moseley M, Fielder A, eds. Amblyopia: A Multidisciplinary Approach. Oxford, UK: Butterworth-Heinemann; 2002:101.

3. Levi DM, Li RW. Perceptual learning as a potential treatment for amblyopia: a mini-review. Vision Res. 2009;49:2535-2549.

4. Levi DM, Polat U. Neural plasticity in adults with amblyopia. Proc Natl Acad Sci U S A. 1996;93:6830-6834.

5. Levi DM, Polat U, Hu YS. Improvement in Vernier acuity in adults with amblyopia: practice makes better. Invest Ophthalmol Vis Sci. 1997;38:1493-1510.

6. Li RW, Levi DM, Klein SA. Perceptual learning improves efficiency by re-tuning the decision 'template' for position discrimination. Nat Neurosci. 2004;7:178-183.

7. Li RW, Provost A, Levi DM. Extended perceptual learning results in substantial recovery of positional acuity and visual acuity in juvenile amblyopia. Invest Ophthalmol Vis Sci. 2007;48:5046-5051.

8. Li RW, Young KG, Hoenig P, Levi DM. Perceptual learning improves visual performance in juvenile amblyopia. Invest Ophthalmol Vis Sci. 2005;46:3161-3168.

9. Polat U, Ma-Naim T, Belkin M, Sagi D. Improving vision in adult amblyopia by perceptual learning. Proc Natl Acad Sci US A. 2004;101:6692-6697.

10. Chen PL, Chen JT, Fu JJ, Chien KH, Lu DW. A pilot study of anisometropic amblyopia improved in adults and children by perceptual learning: an alternative treatment to patching. Ophthalmic Physiol Opt. 2008;28:422-428.

11. Zhou Y, Huang $\mathrm{C}$, Xu P, et al. Perceptual learning improves contrast sensitivity and visual acuity in adults with anisometropic amblyopia. Vision Res. 2006;46:739-750.

12. Huang CB, Zhou Y, Lu ZL. Broad bandwidth of perceptual learning in the visual system of adults with anisometropic amblyopia. Proc Natl Acad Sci U S A 2008;105:4068- 4073.

13. Liu XY, Zhang T, Jia YL, Wang NL, Yu C. The therapeutic impact of perceptual learning on juvenile amblyopia with or without 
previous patching treatment. Invest Ophthalmol Vis Sci. 2011;52 1531-1538.

14. Nazir TA, O'Regan JK. Some results on translation invariance in the human visual system. Spat Vis. 1990;5:81-100.

15. Fiorentini A, Berardi N. Perceptual learning specific for orientation and spatial frequency. Nature. 1980;287:43-44.

16. Karni A, Sagi D. Where practice makes perfect in texture discrimination: evidence for primary visual cortex plasticity. Proc Natl Acad Sci U S A. 1991;88:4966-4970.

17. Karni A, Sagi D. The time course of learning a visual skill. Nature 1993;365:250-252.

18. Poggio T, Fahle M, Edelman S. Fast perceptual learning in visual hyperacuity. Science. 1992;256:1018-1021.

19. Crist RE, Li W, Gilbert CD. Learning to see: experience and attention in primary visual cortex. Nat Neurosci. 2001;4:519-525.

20. Saffell T, Matthews N. Task-specific perceptual learning on speed and direction discrimination. Vision Res. 2003;43:1365-1374.

21. Polat U, Ma-Naim T, Spierer A. Treatment of children with amblyopia by perceptual learning. Vision Res. 2009;49:2599-2603.

22. Qiu Z, Xu P, Zhou Y, Lu ZL. Spatial vision deficit underlies poor sine-wave motion direction discrimination in anisometropic amblyopia. J Vis. 2007;7:7 1-16.

23. Hess RF, Anderson SJ. Motion sensitivity and spatial undersampling in amblyopia. Vision Res. 1993;33:881-896.

24. Li X, Lu ZL, Xu P, Jin J, Zhou Y. Generating high gray-level resolution monochrome displays with conventional computer graphics cards and color monitors. J Neurosci Methods. 2003;130 9-18.

25. Brainard DH. The Psychophysics Toolbox. Spat Vis. 1997;10:433436.

26. Pelli DG. The VideoToolbox software for visual psychophysics: transforming numbers into movies. Spat Vis. 1997;10:437-442.

27. Huang C, Tao L, Zhou Y, Lu ZL. Treated amblyopes remain deficient in spatial vision: a contrast sensitivity and external noise study. Vis Res. 2007;47:22-34.

28. Levitt H. Transformed up-down methods in psychoacoustics. J Opt Soc America A Opt Image Sci Vis. 1971;49(suppl 2):467.

29. Hou F, Huang CB, Lesmes L, et al. qCSF in clinical application efficient characterization and classification of contrast sensitivity functions in amblyopia. Invest Ophthalmol Vis Sci. 2010;51:53655377.

30. Rohaly AM, Owsley C. Modeling the contrast-sensitivity functions of older adults. J Opt Soc Am. 1993;10:1591-1599.

31. Watson AB, Ahumada AJ Jr. A standard model for foveal detection of spatial contrast. J Vis. 2005;5:717-740.

32. Watson AB. Temporal sensitivity. In: Boff K, Kaufman L, Thomas J, eds. Handbook of Perception and Human Performance. New York: Wiley; 1986.

33. Lesmes LA, Lu ZL, Baek J, Albright TD. Bayesian adaptive estimation of the contrast sensitivity function: the quick CSF method. $J$ Vis. 2010;10:1711-1721.
34. Kiorpes L, Movshon JA. Development of sensitivity to visual motion in macaque monkeys. Vis Neurosci. 2004;21:851-859.

35. Simmers AJ, Ledgeway T, Hess RF. The influences of visibility and anomalous integration processes on the perception of global spatial form versus motion in human amblyopia. Vision Res. 2005;45: $449-460$.

36. Simmers AJ, Ledgeway T, Hess RF, McGraw PV. Deficits to global motion processing in human amblyopia. Vision Res. 2003;43:729738.

37. Constantinescu T, Schmidt L, Watson R, Hess RF. A residual deficit for global motion processing after acuity recovery in deprivation amblyopia. Invest Ophthalmol Vis Sci. 2005;46:3008-3012.

38. Albright TD. Direction and orientation selectivity of neurons in visual area MT of the macaque. J Neurophysiol. 1984;52:11061130.

39. Morrone MC, Burr DC, Vaina LM. Two stages of visual processing for radial and circular motion. Nature. 1995;376:507-509.

40. Watanabe $\mathrm{O}$, Kikuchi $\mathrm{M}$. Hierarchical integration of individual motions in locally paired-dot stimuli. Vision Res. 2006;46:82-90.

41. Welch $\mathrm{L}$. The perception of moving plaids reveals two motionprocessing stages. Nature. 1989;337:734-736.

42. Lesmes LA, Gepshtein S, Lu Z-L, Albright T. Rapid estimation of the spatiotemporal contrast sensitivity surface. J Vis. 2009;9:696-696.

43. McKee SP, Levi DM, Movshon JA. The pattern of visual deficits in amblyopia. J Vis. 2003;3:380 - 405 .

44. Huang CB, Lu ZL, Zhou Y. Mechanisms underlying perceptual learning of contrast detection in adults with anisometropic amblyopia. J Vis. 2009;9:24 21-14.

45. Dosher BA, Lu ZL. Perceptual learning reflects external noise filtering and internal noise reduction through channel reweighting. Proc Natl Acad Sci U S A. 1998;95:13988-13993.

46. Fahle M, Edelman S. Long-term learning in vernier acuity: effects of stimulus orientation, range and of feedback. Vision Res. 1993;33: 397-412.

47. Schoups AA, Vogels R, Orban GA. Human perceptual learning in identifying the oblique orientation: retinotopy, orientation specificity and monocularity. J Physiol. 1995;483:797-810.

48. Ahissar M, Hochstein S. Task difficulty and the specificity of perceptual learning. Nature. 1997:387:401-406.

49. Huang X, Lu H, Tjan BS, Zhou Y, Liu Z. Motion perceptual learning: when only task-relevant information is learned. J Vis. 2007;7:14 $11-10$.

50. Xiao LQ, Zhang JY, Wang R, Klein SA, Levi DM, Yu C. Complete transfer of perceptual learning across retinal locations enabled by double training. Curr Biol. 2008;18:1922-1926.

51. Zhang JY, Zhang GL, Xiao LQ, Klein SA, Levi DM, Yu C. Rule-based learning explains visual perceptual learning and its specificity and transfer. J Neurosci. 30:12323-12328.

52. Lu ZL, Sperling G. Three-systems theory of human visual motion perception: review and update. J Opt Soc Am A Opt Image Sci Vis. 2001;18:2331-2370. 